\title{
Biological Rhythms, Metabolism and Function in Feathered Dinosaurs; As Determined by Biostatistics
}

\author{
Clifford Qualls ${ }^{1}$, Spencer G Lucas ${ }^{2}$, Mike Spilde ${ }^{3}$ and Otto Appenzeller ${ }^{2,4 *}$
}

${ }^{1}$ Department of Mathematics and Statistics, University of New Mexico, Albuquerque NM 87131, USA

${ }^{2}$ New Mexico Museum of Natural History and Science Albuquerque, New Mexico 87104, USA

${ }^{3}$ Department of Earth and Planetary Sciences, Institute of Meteoritics, University of New Mexico Albuquerque, NM 87131, USA

${ }^{4} \mathrm{New}$ Mexico Health Enhancement and Marathon clinics Research Foundation, Albuquerque NM 87122, USA

\begin{abstract}
Rotation of the earth around the sun paces daily biologic rhythms (circadian rhythms). Additional rhythms spanning days are mutidien. The energy for biologic rhythms is provided by metabolism.

We measured biologic rhythms in dinosaur's fossilized feather and rachis imprints and in contemporaneous wild turkey tail-feather.

Daily growth lines were measured in 9 photographs of dinosaur feather-imprints. They were from an enantiornithine bird (Mesozoic 245-265 million years), from a troodontid theropod (Cretaceous $\sim 160$ million years) and from Sinosauropteryx (Early Cretaceous; $\sim 125$ million years; rachis only). We measured 27 growth lines and 39 rachis intervals in the turkey feather. We compared our measurements in the dinosaurs to those in the modern feather. We used biometrics to analyze the measurements, we found circadian and multidien rhythms in all feathers. The gliding Microraptor had large feathers. In contrast, the feathered dinosaurs had smaller feathers. Wild turkey feathers were of intermediate size.

We conclude, based on measurements and statistically identified spectral peaks, that circadian and multidien rhythms are present in feather imprints of dinosaurs and in extant birds similar to those described in mammals. Feather growth is related to metabolism, to function and to body mass; this suggests a similar metabolism in feathered dinosaurs and modern birds.
\end{abstract}

Keywords: Biometrics power spectra; Feathered dinosaurs; Metabolism; Body mass; Multidien rhythms; Circadian rhythms

\section{Introduction}

The energy necessary for life and its rhythms is provided by metabolism. The changes in metabolism induced by the sun are synchronous with the sun rising every 24 hours, which is they are circadian ( 24 hours). However, additional biologic rhythms exist that extend over several days or more that are linked to metabolism and not to celestial events; they are termed mutidien [1].

Here we show that biologic rhythms can be derived from fossil imprints left in rock formations of feathered creatures that lived millions of years ago. We compared the imprints of feathers' growth lines that measure circadian growth from the past with the corresponding measurements from extant birds. We also modeled multidien biologic rhythms in these animals.

Circadian rhythms are biological cycles such as temperature fluctuations recurring approximately every 24 hours synchronous with celestial events that are predicated by the rotation of the earth around the sun. Such cycles are ubiquitous in living beings from unicellular protists living in the sea to giants such as extant elephants and whales to even titanic creatures such as extinct Sauropod dinosaurs.

Multidien rhythms occur independently of cosmic inputs [1] and are predicated on fluctuation of metabolic activities which are related to metabolic demand-fluctuations induced by environmental cues such as altitude of residence or the demands of acclimatization.

\section{Material and Methods}

Twenty four rachis imprints were measured in the figures published in ref. [2]. A wild turkey tail feather was used to measure 27 circadian growth lines and 39 rachis growth intervals (by scanning electron microscopy) (Figure 1). Ninety three feather imprints were measured in the figures in refs. [3-5] (Figure 2).

We modeled growth and metabolism using methods published in ref. [6]. We used allometric methods to estimate the size of organs and their functions in the feathered dinosaurs [7] and wild turkey (Table 1). We statistically adjusted allometric measurements from extant mammals to extant birds.

\section{Results}

The results are shown in Table 1. The presumed glider had large feathers that grew rapidly. The other feathered dinosaurs had slower growth rates per day and slower growth per multidien rhythms. We found that birds, like mammals, have circadian and multidien biologic rhythms [1].

We used allometric values to determine organ weights and physiologic functions, as given for mammals [7]. We adjusted these values using the coefficient $(\mathrm{x} 1.15)$ and exponent $\mathrm{x} 1.04$ for birds as

*Corresponding author: Appenzeller $O$, New Mexico Museum of Natural History and Science Albuquerque, New Mexico 87104, USA, Tel: +1 505-841-2800; E-mail: ottoarun12@aol.com

Received November 10, 2016; Accepted December 09, 2016; Published December 12, 2016

Citation: Qualls C, Lucas SG, Spilde M, Appenzeller O (2016) Biological Rhythms, Metabolism and Function in Feathered Dinosaurs; As Determined by Biostatistics. J Biom Biostat 7: 326. doi:10.4172/2155-6180.1000326

Copyright: $\odot 2016$ Qualls C, et al. This is an open-access article distributed under the terms of the Creative Commons Attribution License, which permits unrestricted use, distribution, and reproduction in any medium, provided the original author and source are credited. 
given on the Internet (BIO 554/754 Ornithology). Exceptions are for heart weight (1/9) and brain weight (1/12). A further exception is the heart rate value given for the pigeon (coefficient to match known pigeon heart rate published on the Internet).

\section{Discussion}

Bioarcheology is a cross disciplinary endeavor spanning the fields

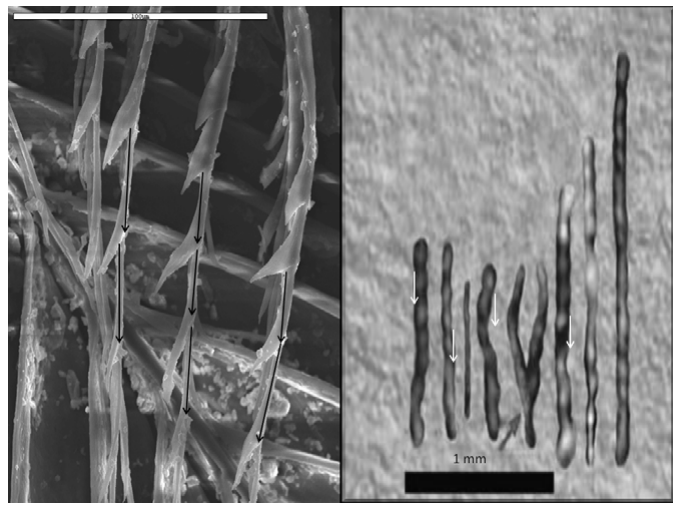

Figure 1: Rachis growth intervals. Left contemporary wild turkey feather barbules (SEM). Right rachis structures made of collagen (also, see discussion) in Sinosauropteryx. Modified from [2]. The arrow length is equivalent to the growth intervals in these structures.

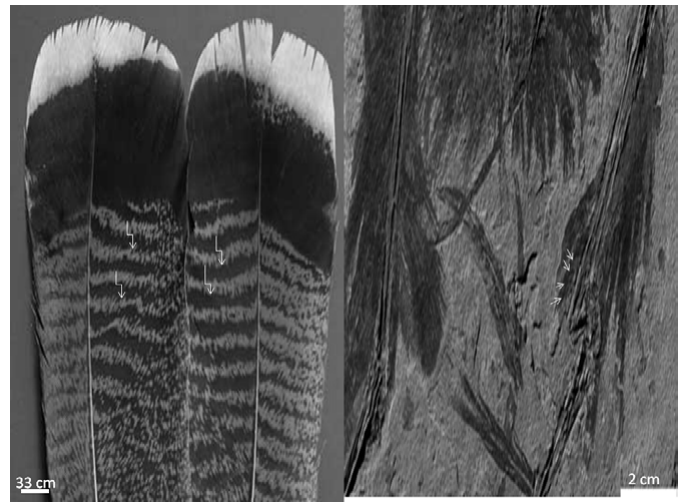

Figure 2: Circadian growth lines. Left Wild turkey feather (broken arrows) fig available on internet; right feathered dinosaur (between arrows) (modified from [5]. The combined light and dark lines of the feather or feather imprint (right) reflect growth of the feather over a $\sim 24$ hour period. of archeology and biology. The best preserved remains for study in bioarcheology are bone, teeth, hair and feather imprints in rocks that formed millions of years ago. We present evidence, based on measurements of growth-intervals of feathers, in rock imprints left by the feathers of dinosaurs millions of years ago, that these animals had both circadian and multidien rhythms. We also show that by using allometric techniques, that is estimates of the relationship of body size to anatomy and physiology, we could deduce the growth rates of the feathers and hence metabolism and function in feathered dinosaurs.

Biological timing is also evident in aging, life history events such as age at maturation and life span. Additionally, recurring growth lines in teeth suggest that tooth growth is influenced by long term rhythms such as circaseptan (7 day) biologic events [1]. Thus, apart from the well studied circadian rhythms, multidien recurring events, independent of astronomical cycles also affect biology. In mammals multidien rhythms have been well demonstrated [1] but evidence for such rhythms in birds has, hitherto, not been presented. Here we provide for the first time evidence that multidien rhythms are also present in extant and extinct birds.

The fossil integument structures in theropod dinosaurs have been accepted as the progenitors of early feathers. This strengthened the view that birds are the evolutionary descendants of theropod dinosaurs [2] However, the chronobiology and physiology of birds that lived million of years ago has not been elucidated.

We show that by using statistical modeling of growth intervals it is possible to deduce biologic rhythms, metabolism and function in these long extinct creatures.

Our modeling is based on validated methods fully described in ref. [6]. Archived materials such as feather imprints left in rock formation that formed millions of years ago bear the growth lines of the feather, the repeat intervals of growth and quiescence of growth, during the life of animals. Because feather growth requires energy to fuel metabolism, the growth lines reflect the chronobiology and metabolism of growing tissues such as feathers and the rachis and its subdivisions, the barbules [6]. The interpretation of the rock prints given in ref. [2] is that these are collagen fibers. However, a continued controversy of whether the presence of collage fibers or feathers left the rock imprints culminated in the discovery of melanosomes in rock imprints that give feathers their color [8]. Irrespective of this controversy our concern here is growth intervals and not with the material that left the rock imprints millions of years ago.

Feather growth is not linear, it occurs in spurts interspersed by

\begin{tabular}{|c|c|c|c|c|c|c|}
\hline \multirow{2}{*}{$\begin{array}{l}\text { Anatomy and Physiology } \\
\text { Parameter }\end{array}$} & \multicolumn{6}{|c|}{ Species } \\
\hline & Pigeon & Wild Turkey & pre-Archaeopteryx & Gliding Microraptor & Nonavian theropod & Sinosauropteryx \\
\hline Body wgt (g) & 450 & 8000 & 240 & 428 & 200 & 240 \\
\hline Heart wgt (g) & 50 & 889 & 27 & 48 & 22 & 27 \\
\hline kidney wgt (g) & 4 & 60 & 2 & 4 & 2 & 2 \\
\hline liver wgt (g) & 16 & 206 & 9 & 16 & 8 & 9 \\
\hline HR (beats/min) & 116 & 55 & 137 & 118 & 143 & 137 \\
\hline Brain (g) & 38 & 667 & 20 & 36 & 17 & 20 \\
\hline O2 Consumption (L/h) & 0.4 & 3.9 & 0.3 & 0.4 & 0.2 & 0.3 \\
\hline Respiratory Freq (/min) & 76 & 35 & 90 & 77 & 95 & 90 \\
\hline Basal Metabolic Rate (kcal/d) & 4.6 & 10.6 & 3.8 & 4.5 & 3.6 & 3.8 \\
\hline Circadian rhythm mm/day & not measured & 7.80 & 5.30 & 18.90 & 4.80 & 0.11 \\
\hline Multidien rhythm (mm/d) & not measured & 26.52 & 12.72 & 94.5 & 139 & 0.374 \\
\hline Multidien rhythm (days/cyc) & not assessed & 3.4 & 2.4 & 5.0 & $\sim 20$ & 3.4 \\
\hline
\end{tabular}

Table 1: Biologic rhythms, growth rates, allometric values for organs and physiologic functions in feathered dinosaurs and extant birds. 
quiescent periods. The frequency or periodicity of the quiescent period, in turn, is determined by metabolic demands imposed by age, health, illness and a multitude of other life events. But the periodicity of feather growth is closely correlated with autonomic nervous system control of metabolism and this ultimately links growth to metabolism in all animals [6].

In modern feathers, and their associated structures, such as the rachis and the barbules, the circadian growth lines can easily be recognized. Based on various methodological evidence such as radio labeling and actual measures it has been establishes that the sum of a dark and a light line found in most extant feathers represent the growth of the feather or barbules over a 24 hour period, that is they are a record of the circadian growth. The persuasive evidence for this has been summarized in Ptilochronology [9]. All growing tissues such as teeth and bone in mammals show growth lines. We find that growth lines are also evident in feather-rachis, the spine of the feather, (Figure 1) and we identified similar structures in feather imprints depicted in reference [2]. The rachis (or barbules) growth lines, however, are multidien, not circadian (Table 1), but, like all growth, they also depend on metabolism rather than on the circadian celestial events [1].

Multidien rhythms are well known in chronobiology [1]. These rhythms do not depend on the rotation of the earth around the sun; rather, they are synchronous with metabolic changes that occur at multidien intervals. Multidien rhythms have been established for mammals [1]. By contrast, bird metabolism has not been studied in sufficient detail to determine the presence of multidien rhythms. Our results imply that these rhythms were present in ancient birds such as feathered dinosaurs, and that they are also found in extant birds.

Because multidien rhythms are tied to metabolic demands they are heavily dependent on environmental factors such as temperature, oxygen availability (altitude of abode) and food abundance. Thus it is not surprising that in avian theropods, like in extant mammals, multidien rhythms varied from 3-5 days/cycle. Of interest is the nonavian theropod in which multidien cycles were $\sim 20$ days/cycle; slow cycling, perhaps related to its inability to fly.

Allometry is a method for studying the relationships between body size and body shape. This method has also been applied, using statistical techniques, to the study of anatomy and physiology [10]. It has been well established that body mass scales to metabolism by a ratio of $\sim 0.75$. Thus, a larger animal has a lower metabolic rate and heart rate than a smaller animal. We applied this method, using the available data, to deduce metabolism, organ weight, heart rate, oxygen consumption and multidien rhythms of the feathered dinosaurs (Table 1).

\section{Conclusion}

In conclusion, we have measured biologic rhythms, metabolism and function in birds that lived millions of years ago. They are similar to those found in extant birds. Multidien rhythms have previously been found in mammals. Here we provide evidence, for the first time, that such rhythms are also present in extant birds and dinosaurs.

\section{Acknowledgements}

New Mexico Health Enhancement and Marathon Clinics Research Foundation (NMHEMC Research Foundation) Albuquerque NM USA for funding this work (Grant \# 10-56)

\section{References}

1. Bromage TG, Idaghdour $Y$, Lacruz RS, Crenshaw TD, Ovsiy O, et al. (2016) The Swine Plasma Metabolome Chronicles "Many Days" Biological Timing and Functions Linked to Growth.

2. Lingham-Soliar T, Feduccia A, Wang X (2007) A new Chinese specimen indicates that 'protofeathers' in the Early Cretaceous theropod dinosaur Sinosauropteryx are degraded collagen fibres. Proc R Soc B 274: 1823-1829.

3. Hu D, Hou L, Zhang L, Xu X (2009) A pre-Archaeopteryx troodontid theropod from China with long feathers on the metatarsus. Nature.

4. Xu X, Zheng X, You H (2009) A new feather type in a nonavian theropod the early evolution of feathers and in Leg feathers in an Early Cretaceous bird of China. Proc Natl Acad Sci 106: 832-834.

5. Zhang F, Zhou Z (2004) Palaeontology: leg feathers in an Early Cretaceous bird. Nature 431: 925.

6. Qualls C, Appenzeller O (2015) Modeling Metabolism and Disease in Bioarcheology. Biomed Res In 2015: 548704.

7. Gunga HC, Suthau T, Bellmann A, Stoinski S, Friedrich A, et al. (2008) A new body mass estimation of Brachiosaurus brancai Janensch 1914 mounted and exhibited at the Museum of Natural History (Berlin, Germany) Fossil Record 11: $33-38$

8. McNamara ME, Briggs DEG, Orr PJ, Field DJ, Wang Z (2013) Experimental maturation of feathers: implications for reconstructions of fossil feather colour. Biol Lett.

9. Grubb TC, Ptilochronology. Feather time and the biology of birds. Oxford University Press.

10. Damuth J (2001) Scaling of growth: plants and animals are not so different. Proc Natl Acad Sci 98: 2113-2114. 